\title{
Chuva de sementes em fragmentos de Floresta Atlântica (São Paulo, SP, Brasil), sob diferentes situações de conectividade, estrutura florestal e proximidade da borda
}

\author{
Vânia Regina Pivello ${ }^{1,3}$, Daniela Petenon ${ }^{1}$, Flávia Moraes de Jesus ${ }^{1}$, Sérgio Tadeu Meirelles ${ }^{1}$, \\ Mariana Morais Vidal ${ }^{1}$, Regina de Azevedo Soares Alonso ${ }^{1}$, Geraldo Antônio Daher Corrêa Franco ${ }^{2}$ e \\ Jean Paul Metzger ${ }^{1}$
}

Recebido em 10/06/2005. Aceito em 12/05/2006

\begin{abstract}
RESUMO - (Chuva de sementes em fragmentos de floresta Atlântica (São Paulo, SP, Brasil), sob diferentes situações de conectividade, estrutura florestal e proximidade da borda). A composição da chuva de sementes permite inferir sobre o desenvolvimento, o direcionamento sucessional e a regeneração de comunidades vegetais. Em paisagens fragmentadas, é grandemente influenciada pela conectividade entre fragmentos remanescentes e pela estrutura da vegetação. Foram comparadas as chuvas de sementes em três fragmentos de Mata Atlântica (Caucaia do Alto, SP), em função de seus tamanhos, graus de conectividade na paisagem, situação de borda e interior, grau de perturbação e características estruturais da vegetação, para verificar a influência desses parâmetros nas respectivas chuvas de sementes. As sementes foram classificadas conforme síndrome de dispersão primária, hábito e tipo funcional das espécies. Foi testada a possível influência da borda sobre esses atributos (qui-quadrado). Padrões entre características dos fragmentos (tamanho, conexão), posição dos coletores (borda, interior) e a abundância dos diferentes diásporos foram explorados por análise de correspondência destendencionada (DCA) e análise de correlação de Spearman. Das 28.873 sementes coletadas, a maioria foi de espécies arbóreas (80,7\%) e zoocóricas (73,7\%). No fragmento "pequeno/isolado" houve predominância de espécies arbóreas tardias. O fragmento "pequeno/conectado" mostrou características opostas às do isolado. O fragmento "grande/fonte", com a maior diversidade, mostrou uma situação bem definida de borda e interior. Com base nesses parâmetros, os padrões encontrados sugerem uma melhor qualidade ecológica do fragmento "pequeno/isolado", seguido do "grande/fonte" e, finalmente, do "pequeno/conectado". Houve uma oposição entre os efeitos de conectividade e estrutura da vegetação, tendo esta sido mais importante na determinação dos padrões encontrados quanto ao hábito, tipo funcional e síndrome de dispersão das espécies das chuvas de sementes do que a conectividade da paisagem.
\end{abstract}

Palavras-chave: Floresta Atlântica, fragmentação de habitat, dispersão de plantas, chuva de sementes, diásporos

\begin{abstract}
Seed rain in Atlantic forest fragments (São Paulo State, SP, Brazil) with different connectivity, forest structure and distance to edge). Information on seed-rain composition of plant communities allows predictions concerning the successional development of the community and its recovery potential. In fragmented landscapes, seed rain is highly influenced by the connectivity among the remaining fragments and by vegetation structure. In this study we compared the seed rain of three fragments of Atlantic forest (Caucaia do Alto, SP), taking into account fragment size, connectivity in the landscape, edge/interior condition, vegetation structure, and previous disturbance, to verify how these parameters affected the seed rain. Seeds were classified according to primary dispersal syndrome, species life form, and functional type. Based on species attributes, we tested for possible edge effects (chi-squared). We searched for relationships among fragment features (size, connectivity), seed trap position (edge, interior), and the abundance of each diaspore type through detrended correspondence analysis (DCA) and Spearman correlation test. The majority of the 28,873 seeds belonged to arboreal ( $80.7 \%$ ) and zoochoric species (73.7\%). Late successional tree species predominated in the "small/isolated" fragment, while the "small/connected" fragment showed opposite characteristics. The "large/source" fragment had the highest species diversity and a well-defined edge. Based on these parameters, patterns point to a better ecological condition in the "small/isolated" fragment, followed by the "large/source", and finally by the "small/connected" fragments. We found a contrast between the effects of connectivity and vegetation structure; the latter was more important than fragment connectivity in determining patterns of life form, functional type and dispersal syndrome of seed-rain species.
\end{abstract}

Key words: Atlantic forest, habitat fragmentation, plant dispersal, seed rain

\section{Introdução}

A dispersão de sementes é um processo fundamental na dinâmica florestal. A chegada de diásporos de diferentes espécies, e seu posterior estabelecimento, irão direcionar o desenvolvimento sucessional e as mudanças na comunidade (Howe \& Smallwood 1982; Fenner 1985; Clark et al. 1999;

\footnotetext{
1 Universidade de São Paulo, Instituto de Biociências, Departamento de Ecologia, Rua do Matão, Travessa 14, 05508-900 São Paulo, SP, Brasil

2 Instituto Florestal, Divisão de Dasonomia, Seção de Ecologia Florestal, Rua do Horto, 02377-000 São Paulo, SP, Brasil

3 Autor para correspondência: vrpivel@usp.br
} 
Hardesty \& Parker 2002).

O tipo e o tamanho dos diásporos, bem como seus principais agentes dispersores, constituem fatores fundamentais na chegada e no estabelecimento das plantas. As síndromes de dispersão predominantes na comunidade permitem inferir sobre a estrutura da vegetação, seu estádio sucessional e seu grau de conservação. Em florestas tropicais úmidas, a maioria das espécies tardias, especialmente em estratos intermediários, é dispersa por animais - principalmente aves -, enquanto que as iniciais são comumente dispersas pelo vento (Harper 1977; Van der Pijl 1982; Terborgh 1990; Guevara \& Laborde 1993; MartínezRamos \& Souto-Castro 1993; Wheelwright 1993). As espécies de dossel, bem como muitas lianas, também estão geralmente associadas à dispersão anemocórica (Howe \& Smallwood 1982). O tipo de agente dispersor influencia a eficiência de dispersão. Os vertebrados são tidos como dispersores de longas distâncias mas são, por outro lado, mais específicos ao ambiente, contrapondo-se ao vento e à água (Gorchov et al. 1993; Wilson 1993). Perturbações nas florestas podem levar à perda direta de animais dispersores ou a alterações na estrutura da vegetação, as quais, por sua vez, também poderão resultar na perda de dispersores. Em conseqüência, são previstas alterações nos processos de auto-manutenção, regeneração e expansão da floresta.

A dispersão dos diásporos é também influenciada pelo padrão de distribuição espacial das plantas e pelas barreiras oferecidas pelo ambiente à dispersão (Venable \& Brown 1993; Webb \& Peart 2001). Em paisagens fragmentadas por atividades humanas, o arranjo espacial (tipo, tamanho, quantidade e localização) dos elementos vegetados remanescentes - dado pelas manchas de vegetação, corredores e trampolins biológicos (stepping stones) e tipo de matriz - é fundamental para a sobrevivência e expansão das comunidades naturais (Collinge 1998; Laurance \& Laurance 1999; Metzger 2000; Godefroid \& Koedam 2003). A proximidade entre os fragmentos remanescentes, assim como os elementos de conexão e a matriz, irão determinar o grau de conectividade estrutural da paisagem (Taylor et al. 1993; Metzger \& Décamps 1997) e, em consequiência, a capacidade de dispersão de propágulos entre os fragmentos. Além de causar isolamento entre os remanescentes da vegetação, a fragmentação de habitats cria bordas abruptas entre esses remanescentes e o entorno desmatado, aumentando em muito os "efeitos de borda": alterações no microclima e no solo das bordas, que levam a mudanças nas comunidades biológicas e afetam vários processos ecológicos (Murcia 1995; Fox et al. 1997; Fahrig 2003).

Uma forma de se inferir sobre os processos iniciais de dispersão em ambientes florestais é por meio da análise da chuva de sementes. Por ser um processo inicial da organização da estrutura e da dinâmica de florestas tropicais, e por favorecer a manutenção do potencial demográfico das populações futuras, sua importância tem sido cada vez mais reconhecida (Janzen 1971; Howe \& Smallwood 1982; Fenner 1985; Tilman 1999; Clark et al. 1999; Hardesty \& Parker 2002). A composição da chuva de sementes é também importante em processos de regeneração da vegetação natural, os quais dependem de fontes de propágulos autóctones e alóctones. Em paisagens fragmentadas, remanescentes florestais maduros agem como fontes de diásporos, e o arranjo espacial entre os fragmentos é determinante da quantidade e qualidade dos propágulos alóctones da chuva de sementes. A taxa de recuperação de áreas degradadas é afetada pela distância de fontes de sementes (Oosterhoorn \& Kappelle 2000).

Estudos que relacionam a eficiência de dispersão de espécies de florestas tropicais com o arranjo espacial dos fragmentos na paisagem e efeitos de borda são ainda escassos, mas alguns exemplos podem ser encontrados em Guevara \& Laborde (1993), MartínezRamos \& Souto-Castro (1993) e Venable \& Brown (1993). No Brasil, esta abordagem é inédita até o momento e o presente estudo pretende iniciar a análise da influência da estrutura da paisagem na dispersão de propágulos.

Desta forma, o objetivo deste estudo foi caracterizar as espécies presentes na chuva de sementes de três fragmentos florestais da mata Atlântica do Sudeste, avaliando as variações nos padrões das sementes em função do tamanho, grau de perturbação, conectividade estrutural na paisagem (conexão a uma fonte de diásporos) e características estruturais da vegetação de cada fragmento, bem como em função da distância de bordas (borda vs interior). Por meio das sementes, as espécies coletadas foram analisadas quanto à síndrome de dispersão predominante, hábito e tipo funcional. Assim, as perguntas que se procurou responder foram: 1) Há influência do tamanho do fragmento sobre o padrão das sementes contidas na chuva de sementes (quanto ao hábito de vida, tipo funcional e síndrome de dispersão das espécies)? 2) Há influência do grau de conectividade estrutural do fragmento na paisagem 
sobre o padrão das sementes contidas na chuva de sementes? 3) Há influência da estrutura da vegetação do fragmento sobre os padrões das sementes contidas na chuva de sementes?

Esperava-se obter uma relação diretamente proporcional entre a quantidade de espécies arbóreas, tardias e zoocóricas e o tamanho do fragmento, seu grau de conectividade na paisagem e a distância da borda, indicando, nestas condições, maior amadurecimento da comunidade e melhores condições para a fauna dispersora (Aizen \& Feinsinger 1994; Beier \& Noss 1998; Laurance \& Laurance 1999; Metzger 2000; Oosterhoorn \& Kappelle 2000; Fahrig 2003).

\section{Material e métodos}

Área de estudo - A área de estudo localiza-se no distrito de Caucaia do Alto, Município de Cotia, SP

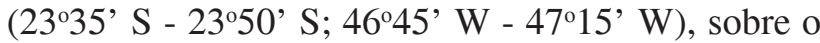
Planalto Cristalino de Ibiúna (Serra de Paranapiacaba, Planalto Atlântico), em altitudes de 850 a 1.100 m. O clima da região é temperado quente e úmido, Cfa (conforme Köppen 1948), com precipitação média anual em torno de $1.340 \mathrm{~mm}$, sendo menor nos meses de abril a setembro, mas sem déficit hídrico (conforme dados do Instituto Agronômico de Campinas CIIAGRO s/data). Predominam os solos Podzólicos Vermelho-Amarelos, Latossolos Vermelho-Amarelos e Cambissolos (Ross \& Moroz 1997), sobre os quais desenvolveu-se originalmente a floresta ombrófila densa montana (conforme Veloso et al. 1991). Entretanto, grande parte das florestas foi derrubada para o fornecimento de madeira e carvão e para o estabelecimento de culturas agrícolas (Dean 1996; Uezu et al. 2005) e hoje, a vegetação natural remanescente é secundária, formada por fragmentos florestais com diferentes graus de perturbação e em vários estádios de regeneração, entremeados a plantações de Eucalyptus spp., Pinus spp. e, principalmente, de hortaliças e frutas. Há, na região, um grande fragmento de mata nativa remanescente (10.700 ha), a Reserva Florestal do Morro Grande, pertencente à Companhia de Saneamento Básico do Estado de São Paulo (SABESP).

A paisagem regional é, portanto, heterogênea, cuja variedade de fitofisionomias reflete a história de uso das terras e as mudanças na cobertura vegetal. Apesar de alterada, a paisagem guarda ainda grande importância ecológica, e tanto a Reserva Florestal do Morro Grande como o conjunto dos fragmentos florestais secundários ao seu redor, pertencem à
Reserva da Biosfera do Cinturão Verde da Cidade de São Paulo (Instituto Florestal de São Paulo 2004).

Caracterização dos fragmentos estudados - Com base na estrutura da vegetação nativa (dada pela estratificação, porte das árvores e formas de vida), foi escolhido um par de fragmentos florestais pequenos (4,75 ha e 5,48 ha), visualmente semelhantes entre si, sendo um deles isolado de outras áreas florestadas por meio de culturas agrícolas (fragmento Carmo Messias) e outro conectado (fragmento Alcides) por meio de um corredor florestal a um fragmento grande (área florestada com 175,10 ha; fragmento Pedroso) o qual, potencialmente, representava uma fonte de diásporos. Os três fragmentos eram essencialmente formados por florestas em estádios intermediários de sucessão, correspondentes a cerca de 50 anos de regeneração após perturbações antropogênicas (Metzger et al. 2003), e circundados principalmente por cultura de hortaliças. Doravante, esses fragmentos serão referidos como "pequeno/isolado", "pequeno/conectado" e "grande/fonte".

Além da presença de corredores, a conectividade dos fragmentos foi caracterizada, de forma descritiva, por três índices: a proximidade dos fragmentos (PROX), formada pela somatória da razão da área de fragmentos vizinhos $\left(\mathrm{m}^{2}\right)$ pelo quadrado da distância borda-a-borda entre o fragmento focal e o fragmento vizinho, num raio de $800 \mathrm{~m}$ a partir da borda do fragmento (sem unidade); a distância (em metros) aos grandes fragmentos da paisagem (ISO), definidos aqui como fragmentos $>50$ ha; e o índice de percolação do habitat de interior (IHP), que é o número de dilatações (Serra 1982) necessárias para se obter percolação de área nuclear num entorno de $800 \mathrm{~m}$ do centro do fragmento (i.e., numa área de 256 ha no entorno de cada fragmento) (Metzger \& Décamps 1997). A conectividade do fragmento aumenta quanto maior o valor de PROX, menor a distância aos grandes fragmentos e maior o grau de percolação (valores de IHP próximos de zero). A vizinhança de $800 \mathrm{~m}$ foi escolhida a fim de incluir os principais remanescentes do entorno imediato dos fragmentos focais, e que teriam mais chance de contribuir para a chuva de sementes.

Ainda, os fragmentos foram caracterizados por três outros parâmetros: a área total (ha); a área nuclear (ha), que é a área do fragmento excluindo-se bordas de $50 \mathrm{~m}$; e um índice de qualidade florestal (QUALI), sendo este a porcentagem do fragmento em estádio médio/avançado menos a porcentagem do fragmento em estádio inicial/médio (\%). Esses valores foram obtidos a partir de um mapa de uso e cobertura das 
terras, produzido por interpretação de fotografias aéreas (abril/2000), na escala 1:10.000 (Metzger et al. 2003). Os estádios sucessionais foram definidos conforme a Resolução Conjunta SMA/IBAMA/SP-1, de 17/02/1994.

Para qualificar a vegetação nos fragmentos, foram utilizados alguns parâmetros estruturais, medidos por L. Alves \& J.P. Metzger (dados não publicados): número médio de indivíduos arbóreos com diâmetro à altura do peito (DAP) $>5 \mathrm{~cm}$, por hectare; número médio de árvores com DAP $>5 \mathrm{~cm}$ ocupadas por bromélias, por hectare; altura média de árvores com DAP> $5 \mathrm{~cm}$; porcentagem de abertura do dossel, medida com esferodensiômetro. Os autores também calcularam um índice de perturbação para os fragmentos $($ zero $=$ sem impacto a $1=$ impacto máximo), obtido pela somatória de vários fatores de impacto ambiental negativo, tais como: corte seletivo de árvores, presença de lixo, indício de fogo, indício de caça, clareiras antropogênicas, densidade de trilhas, reflorestamento, corte de sub-bosque, entrada de gado. Esse índice também foi usado para qualificar a vegetação.

Monitoramento da chuva de sementes - Para coletar os diásporos, foram instalados 54 coletores circulares de sementes, confeccionados com tela de nylon (malha $=1 \mathrm{~mm})$, com área interna de $0,5 \mathrm{~m}^{2} \mathrm{e}$ profundidade do bojo de aproximadamente $15 \mathrm{~cm}$, suspensos a 80-90 cm do solo por meio de estacas, a fim de evitar a coleta de sementes de espécies herbáceas. Cada fragmento recebeu 18 coletores, tendo sido 9 dispostos a $10 \mathrm{~m}$ da borda do fragmento e 9 no centro, arranjados em trios, que passaram a ser as unidades amostrais (Fig. 1). A borda do fragmento era determinada por uma estrada de terra ou trilha, ou por mudança abrupta no uso da terra. No caso dos fragmentos pequenos, os coletores instalados no centro distavam cerca de 50-60 m da borda e, no caso do fragmento "grande/fonte", cerca de $400 \mathrm{~m}$ da borda.

Uma investigação prévia testou a variação entre o número de diásporos depositados em coletores das bordas dos fragmentos pequenos voltadas em direção ao fragmento "grande/fonte" e naqueles voltados em direção oposta. Não tendo sido encontrada diferença significativa, foi mantido o padrão de disposição dos coletores das bordas voltados sempre em direção ao fragmento "grande/fonte".

Foram feitas 11 coletas (março/2001 a janeiro/2002). O material depositado nos coletores foi seco a $60{ }^{\circ} \mathrm{C}$, tendo-se separado os diásporos (sementes e frutos) de outras partes vegetais. Para as análises,

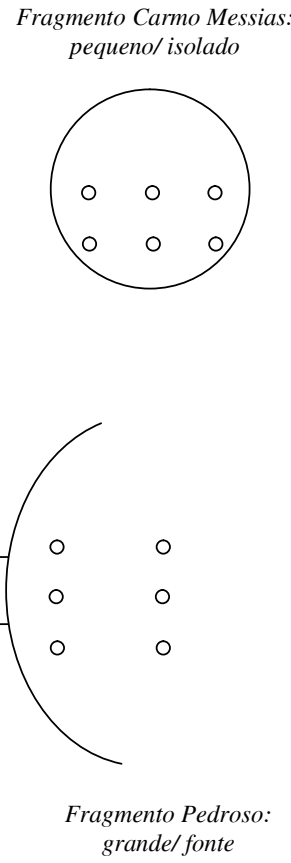

Figura 1. Diagrama esquemático da distribuição dos coletores no campo. Cada ponto representa um trio de coletores.

foram considerados os diásporos maiores que $1 \mathrm{~mm}$, os quais foram identificados no maior nível de detalhe taxonômico possível e contados, seletivamente, por nível taxonômico. $\mathrm{O}$ número de sementes em frutos intactos foi estimado conforme a média de sementes contidas em frutos do respectivo nível taxonômico. A partir daí, as sementes - e não mais os diásporos - foram considerados para as análises.

Análise dos dados - Foi calculada a densidade relativa de sementes de cada espécie por fragmento, tanto na borda como no seu interior, conforme Mueller-Dombois \& Ellenberg (1974):

$$
\mathrm{DRi}=100 \mathrm{ni} / \mathrm{N} \text {; }
$$

onde $\mathrm{DRi}=$ densidade relativa de sementes da espécie i $(\%) ;$ ni $=$ número de sementes da espécie i no sítio considerado; $\mathrm{N}=$ número total de sementes amostradas no sítio considerado.

A diversidade específica na borda e no centro de cada fragmento foi avaliada por meio do índice de diversidade de Shannon ( $\left.H^{\prime}\right)$, os quais foram comparados por meio do teste t de Hutchenson (Zar 1999).

Com base na morfologia do diásporo, no conhecimento da respectiva espécie e na literatura (Gandolfi 1991; Lorenzi 1992; Barroso et al. 1999), cada espécie foi classificada quanto à síndrome predominante de dispersão em anemocórica, zoocórica 
ou autocórica e, conforme o tipo funcional, em exótica, inicial (incluindo espécies pioneiras e secundárias iniciais, no processo sucessional), tardia (incluindo espécies secundárias tardias e climáxicas) ou de subbosque (espécies exclusivamente umbrófilas). Conforme o hábito, o grupo taxonômico foi classificado em árvore, arbusto, sub-arbusto ou liana.

Foi testada a hipótese de independência entre a posição dos coletores (borda ou centro) e os atributos - hábito, síndrome de dispersão e tipo funcional das espécies -, utilizando-se tabelas de contingência, analisadas por testes de qui-quadrado. A independência entre a posição dos coletores e os atributos das sementes foi avaliada separadamente para cada fragmento.

A exploração de padrões na relação entre características dos fragmentos (tamanho, conexão a uma fonte de diásporos), posição dos coletores (centro ou borda) e a incidência de tipos de diásporos e suas abundâncias foi feita por meio de uma ordenação baseada no procedimento de análise de correspondência do tipo DCA (Jongman et al. 1996). A análise de ordenação foi baseada numa matriz contendo o grupo taxonômico e o número de sementes classificadas quanto ao hábito, síndrome de dispersão, tipo funcional e sua localização no fragmento. Foram utilizadas apenas espécies com ocorrência mínima em 2 fragmentos. Foram feitas análises de variância unidirecionais com base nos valores dos escores das espécies obtidos nos dois primeiros eixos da DCA, de forma a confirmar associações identificadas nessa análise.

Os escores obtidos para as espécies no primeiro eixo da ordenação foram agrupados em cinco intervalos, contendo de 11 a 14 espécies. Para cada intervalo, foram calculadas as freqüências dos atributos (hábito, dispersão e tipo funcional). As proporções assim obtidas foram correlacionadas com o valor ordinal atribuído à posição do intervalo no gradiente definido no primeiro eixo, empregando-se a correlação de pontos de Spearman (Zar 1999).

A conectividade da paisagem, a estrutura florestal e o grau de perturbação foram analisados de forma qualitativa, na busca de melhor entendimento das diferenças observadas entre fragmentos e/ou coletores. Neste caso, análises quantitativas não foram possíveis devido ao pequeno número de fragmentos amostrados.

\section{Resultados}

Caracterização dos fragmentos estudados - O fragmento "grande/fonte", com área total de 175,10 ha, apresentou cerca de 118 ha de área nuclear, coberta por floresta em estádios mais avançados de sucessão (QUALI) (Tab. 1). Os fragmentos pequenos, devido à sua pequena área total, apresentaram pouca área nuclear, ligeiramente superior e com maior porcentagem de floresta madura (QUALI) no fragmento isolado do que no conectado (Tab. 1). Os índices PROX, ISO e IHP (Tab. 1) confirmaram a baixa proximidade do fragmento "pequeno/isolado" a remanescentes florestais vizinhos e sua distância a uma grande fonte de propágulos, contrariamente ao fragmento "pequeno/conectado" (Tab. 1). Também quanto à estrutura da vegetação, os dois fragmentos pequenos são distintos: o isolado apresentou árvores altas e dossel bem fechado, devido à presença de diversos indivíduos arbóreos grandes e frondosos (o que é bem evidente em campo), bem como uma quantidade de bromélias bem superior à do fragmento "pequeno/ conectado", além do menor índice de perturbação entre os três fragmentos analisados (Tab. 2).

Caracterização das chuvas de sementes - Foram coletadas 27.873 sementes, nos três fragmentos analisados, pertencentes a 28 famílias e 61 espécies

Tabela 1. Caracterização dos fragmentos selecionados na região de Caucaia do Alto, Município de Cotia, SP, quanto à sua estrutura espacial e da paisagem do entorno. (QUALI = índice de qualidade florestal; PROX = índice que indica a proximidade entre fragmentos; ISO = índice que indica o grau de isolamento do fragmento; IHP = índice de percolação do habitat de interior). A descrição dos índices encontra-se no texto. (Dados extraídos de Metzger et al. 2003). Todos os índices calculados, exceto o IHP, constam do software Fragstats, versão 3.3 (McGarigal \& Marks 1995). O índice IHP foi criado por Metzger \& Décamps (1997).

\begin{tabular}{|c|c|c|c|c|c|c|c|}
\hline Fragmento & Classificação & $\begin{array}{l}\text { Área total } \\
\text { (ha) }\end{array}$ & $\begin{array}{c}\text { Área nuclear } \\
\text { (ha) }\end{array}$ & $\begin{array}{l}\text { QUALI } \\
(\%)\end{array}$ & PROX & $\begin{array}{l}\text { ISO } \\
(\mathrm{m})\end{array}$ & IHP \\
\hline Pedroso & grande/fonte & 175,10 & 117,91 & 100 & 1721,15 & 0 & 0 \\
\hline C. Messias & pequeno/isolado & 5,48 & 1,08 & 100 & 51,91 & 1.210 & 27 \\
\hline Alcides & pequeno/conectado & 4,75 & 0,79 & 84 & 850,76 & 45 & 4 \\
\hline
\end{tabular}


Tabela 2. Características estruturais dos fragmentos estudados (Caucaia do Alto, SP), e índice de perturbação, segundo L. Alves \& J.P. Metzger (dados não publicados). (arv $>5 \mathrm{~cm}=$ número médio de indivíduos arbóreos com diâmetro à altura do peito [DAP] $>5 \mathrm{~cm}$, por hectare; bromélia = número médio de árvores com DAP $>5 \mathrm{~cm}$ ocupadas por bromélias, por hectare; altura = altura média de árvores com DAP > $5 \mathrm{~cm}$; abertura do dossel = porcentagem de abertura do dossel; índice de perturbação obtido conforme explicações no texto).

\begin{tabular}{lccccc}
\hline Fragmento & arv $>5 \mathrm{~cm}$ ha & Bromélia & Altura & $\begin{array}{c}\text { Abertura do dossel } \\
(\%)\end{array}$ & $\begin{array}{c}\text { Índice de } \\
\text { perturbação }\end{array}$ \\
\hline Pequeno/conectado & $1.107,7$ & 61,5 & 11,36 & 1,4 & 0,28 \\
Pequeno/isolado & $1.040,0$ & 153,8 & 11,01 & 0,9 & 0,15 \\
Grande/fonte & $1.838,5$ & 261,5 & 10,03 & 1,6 & 0,34 \\
\hline
\end{tabular}

ou morfo-espécies. As famílias mais freqüentes foram: Caesalpinaceae, Lauraceae, Melastomataceae, Myrtaceae, Rubiaceae, Sapindaceae e Solanaceae (Tab. 3). As espécies mais abundantes foram Clethra scabra (Clethraceae) e Gochnatia polymorpha (Asteraceae) (Tab. 4).

Considerando-se os grupos taxonômicos cujas sementes foram classificadas quanto ao hábito, síndrome de dispersão e tipo funcional (Tab. 3), a maioria das sementes coletadas foi de espécies arbóreas (80,7\% do total) e zoocóricas $(73,7 \%)$. Apenas duas espécies foram classificadas como autocóricas $(3,5 \%)$. Quanto ao tipo funcional, predominaram as espécies iniciais $(54,8 \%$ do total) sobre as tardias $(32,2 \%)$. Apenas uma espécie foi reconhecida como exótica (Eriobotrya japonica, Rosaceae), tendo contribuído com 3,2\% do total de sementes (Tab. 4). Dentre as espécies zoocóricas, tanto espécies tardias como iniciais foram bem representadas; entre as anemocóricas, predominaram as iniciais (Tab. 3).

A densidade de sementes foi bem maior para os fragmentos pequenos, especialmente o conectado ("pequeno/conectado": 0,373 sementes $\mathrm{m}^{2}$; "pequeno/ isolado": 0,110 sementes $\mathrm{m}^{2}$ ), do que para o "grande/ fonte" $\left(0,002\right.$ sementes $\left.\mathrm{m}^{2}\right)$, em grande parte devido à abundância de pequenas sementes de espécies anemocóricas, como Clethra scabra (Clethraceae). No fragmento "pequeno/conectado", $75 \%$ das sementes coletadas eram de Clethra scabra e essa espécie foi muito abundante tanto nos coletores da borda como nos situados ao centro. A segunda espécie mais abundante no fragmento "pequeno/conectado" foi Gochnatia polimorfa (Asteraceae), com maior número de sementes na borda, contribuindo com $13 \%$ do total (Tab. 4). Essa espécie foi a mais abundante no fragmento "pequeno/isolado", representando $42,8 \%$ das sementes coletadas, seguida por Ilex paraguayensis (Aquifoliaceae) $(31,5 \%)$, ambas com maior abundância no centro desse fragmento. Serjania sp. (Sapindaceae), uma liana, ocorreu em grande quantidade na borda do fragmento "pequeno/isolado", mas foi ausente em seu interior (Tab. 4). No fragmento "grande/fonte", predominaram as espécies Gochnatia polymorpha $(23,9 \%)$ - que ocorreu especialmente na borda -, Myrsine ferruginea (Myrsinaceae) $(21,0 \%)$ e Lamanonia ternata (Cunoniaceae) (16,3\%), estas mais abundantes no seu interior. As espécies Psychotria sessilis e P. suterella ocorreram em maior densidade apenas na borda (Tab. 4).

A riqueza específica entre os três fragmentos variou pouco, tendo-se encontrado um total de 37 espécies no fragmento "grande/fonte", 38 no fragmento "pequeno/conectado" e 34 no "pequeno/isolado". No entanto, ao se comparar a diversidade específica em suas bordas e interiores, por meio do índice de Shannon (H') (Tab. 5), todos os valores obtidos foram significativamente diferentes $(p<0,001)$, tendo o fragmento "grande/fonte" apresentado diversidade superior, especialmente em seu interior. $\mathrm{O}$ fragmento "pequeno/conectado", por outro lado, foi o que obteve os menores índices de diversidade, especialmente em seu interior (Tab. 5).

Análise das chuvas de sementes - $\mathrm{Na}$ análise de correspondência (DCA), os dois primeiros eixos de escores responderam por $55 \%$ (respectivamente $37 \%$ e $18 \%$ para o primeiro e o segundo eixos) do conteúdo total de informação contido na matriz de abundância de sementes e sítios de coleta (fragmento/borda ou centro). O primeiro eixo mostra um gradiente longo, polarizado pelos fragmentos "pequeno/conectado" e "pequeno/isolado", onde os sítios de coleta correspondentes às bordas e centros desses fragmentos apresentam escores próximos, individualizando cada fragmento pequeno (Fig. 2). O segundo eixo foi representado por um gradiente curto, que permite distinguir, principalmente, a borda e o centro do fragmento "grande/fonte", evidenciadas pela maior distância dos escores nesse eixo; isso não foi 
Tabela 3. Espécies vegetais cujas sementes foram coletadas nos fragmentos florestais estudados (Caucaia do Alto, SP), classificadas conforme o tipo funcional, hábito de vida e síndrome de dispersão primária ( $\mathrm{SC}=$ sem classificação).

\begin{tabular}{|c|c|c|c|}
\hline Família/Espécie & Tipo Funcional & Hábito & Síndrome de dispersão \\
\hline \multicolumn{4}{|l|}{ ANNONACEAE } \\
\hline Guatteria sp. & $\mathrm{SC}$ & arbóreo & zoocoria \\
\hline Xylopia sp. & $\mathrm{SC}$ & arbóreo & zoocoria \\
\hline \multicolumn{4}{|l|}{ AQUIFOLIACEAE } \\
\hline Ilex paraguayensis Hook. & tardia & arbóreo & zoocoria \\
\hline \multicolumn{4}{|l|}{ ARECACEAE } \\
\hline Syagrus romanzoffiana (Cham.) Glassman & inicial & arbóreo & zoocoria \\
\hline \multicolumn{4}{|l|}{ ASTERACEAE } \\
\hline Gochnatia polymorpha (Less.) Cabrera & inicial & arbóreo & anemocoria \\
\hline Stifftia chrysantha Mikan & $\mathrm{SC}$ & arbóreo & anemocoria \\
\hline \multicolumn{4}{|l|}{ BIGNONIACEAE } \\
\hline Bignoniaceae & $\mathrm{SC}$ & liana & SC \\
\hline \multicolumn{4}{|l|}{ BORAGINACEAE } \\
\hline Cordia ecalyculata Vell. & tardia & arbóreo & zoocoria \\
\hline Cordia sp. & $\mathrm{SC}$ & arbóreo & zoocoria \\
\hline \multicolumn{4}{|l|}{ CAESALPINACEAE } \\
\hline Copaifera trapezifolia Hayne & tardia & arbóreo & zoocoria \\
\hline Sclerolobium denudatum Vog. & inicial & arbóreo & anemocoria \\
\hline Caesalpinaceae 1 & $\mathrm{SC}$ & SC & $\mathrm{SC}$ \\
\hline \multicolumn{4}{|l|}{ CANELLACEAE } \\
\hline Capsicodendron dinisii (Schwacke) Occhioni & tardia & arbóreo & $\mathrm{SC}$ \\
\hline \multicolumn{4}{|l|}{ CANELLACEAE } \\
\hline Capsicodendron sp. & SC & $\mathrm{SC}$ & zoocoria \\
\hline \multicolumn{4}{|l|}{ CLETHRACEAE } \\
\hline Clethra scabra Pers. & inicial & arbóreo & anemocoria \\
\hline \multicolumn{4}{|l|}{ CUNONIACEAE } \\
\hline Lamanonia ternata Vell. & inicial & arbóreo & anemocoria \\
\hline \multicolumn{4}{|l|}{ EUPHORBIACEAE } \\
\hline Pera glabrata (Schott) Poepp. ex Baill. & inicial & arbóreo & autocoria \\
\hline \multicolumn{4}{|l|}{ FLACOURTICAEAE } \\
\hline Casearia sylvestris Sw. & inicial & arbóreo & zoocoria \\
\hline \multicolumn{4}{|l|}{ LAURACEAE } \\
\hline Ocotea puberula (Rich.) Nees & tardia & arbóreo & zoocoria \\
\hline Ocotea $\mathrm{sp}$ & $\mathrm{SC}$ & arbóreo & zoocoria \\
\hline Lauraceae 1 & SC & arbóreo & zoocoria \\
\hline Lauraceae 2 & SC & arbóreo & zoocoria \\
\hline Lauraceae 3 & $\mathrm{SC}$ & arbóreo & zoocoria \\
\hline \multicolumn{4}{|l|}{ MALPIGHIACEAE } \\
\hline Heteropterys sp. & $\mathrm{SC}$ & liana & anemocoria \\
\hline Malpighiaceae & $\mathrm{SC}$ & liana & anemocoria \\
\hline \multicolumn{4}{|l|}{ MELASTOMATACEAE } \\
\hline Leandra sp. 1 & $\mathrm{SC}$ & arbusto & zoocoria \\
\hline Leandra sp. 2 & SC & arbusto & zoocoria \\
\hline Miconia sp. & inicial & $\mathrm{SC}$ & zoocoria \\
\hline Tibouchina pulchra (Cham.) Cogn. & inicial & arbóreo & anemocoria \\
\hline \multicolumn{4}{|l|}{ MELIACEAE } \\
\hline Cedrela fissilis Vell. & tardia & arbóreo & anemocoria \\
\hline C. odorata L. & tardia & arbóreo & anemocoria \\
\hline \multicolumn{4}{|l|}{ MIMOSACEAE } \\
\hline Piptadenia gonoacantha (Mart.) J.F. Macbr. & inicial & arbóreo & autocoria \\
\hline \multicolumn{4}{|l|}{ MYRSINACEAE } \\
\hline Myrsine ferruginea (Ruiz \& Pav.) Spreng. & inicial & arbóreo & zoocoria \\
\hline MYRTACEAE & & & \\
\hline Calyptranthes sp. & sub-bosque & arbóreo & zoocoria \\
\hline Eugenia $\mathrm{sp}$. & $\mathrm{SC}$ & arbóreo & zoocoria \\
\hline
\end{tabular}


Tabela 3 (continuação)

\begin{tabular}{|c|c|c|c|}
\hline Família/Espécie & Tipo Funcional & Hábito & Síndrome de dispersão \\
\hline Gomidesia sp. & $\mathrm{SC}$ & arbóreo & zoocoria \\
\hline Myrcia sp. & $\mathrm{SC}$ & arbóreo & zoocoria \\
\hline Psidium cattleyanum Weinw. & inicial & arbóreo & zoocoria \\
\hline Psidium sp. & $\mathrm{SC}$ & arbóreo & zoocoria \\
\hline Myrtaceae 1 & $\mathrm{SC}$ & arbóreo & zoocoria \\
\hline Myrtaceae 2 & SC & arbóreo & zoocoria \\
\hline Myrtaceae 3 & $\mathrm{SC}$ & arbóreo & zoocoria \\
\hline \multicolumn{4}{|l|}{ NYCTAGINACEAE } \\
\hline Pisonia ambigua Heimerl & tardia & arbóreo & zoocoria \\
\hline \multicolumn{4}{|l|}{ PASSIFLORACEAE } \\
\hline Passiflora sp. & $\mathrm{SC}$ & liana & zoocoria \\
\hline \multicolumn{4}{|l|}{ RANUNCULACEAE } \\
\hline Clematis sp. & $\mathrm{SC}$ & liana & anemocoria \\
\hline \multicolumn{4}{|l|}{ ROSACEAE } \\
\hline Eriobotrya japonica (Thunb.) Lindl. & exótica & arbóreo & zoocoria \\
\hline Prunus myrtifolia Urb. & tardia & arbóreo & zoocoria \\
\hline \multicolumn{4}{|l|}{ RUBIACEAE } \\
\hline Posoqueria acutifolia Mart. & tardia & arbóreo & zoocoria \\
\hline Psychotria sessilis (Vell.) Müll. Arg. & sub-bosque & sub-arbustivo & zoocoria \\
\hline P. suterella Müll. Arg. & sub-bosque & sub-arbustivo & zoocoria \\
\hline \multicolumn{4}{|l|}{ RUTACEAE } \\
\hline Zanthoxylum rhoifolium Lam. & inicial & arbóreo & zoocoria \\
\hline \multicolumn{4}{|l|}{ SAPINDACEAE } \\
\hline Allophylus edulis (A. St.-Hil.) Niederl. & inicial & arbóreo & zoocoria \\
\hline Allophylus sp. & inicial & arbóreo & zoocoria \\
\hline Cupania oblongifolia Mart. & inicial & arbóreo & zoocoria \\
\hline Serjania sp. & $\mathrm{SC}$ & liana & anemocoria \\
\hline Sapindaceae & SC & $\mathrm{SC}$ & $\mathrm{SC}$ \\
\hline \multicolumn{4}{|l|}{ SOLANACEAE } \\
\hline Solanum argenteum Blanch. ex Dun. & $\mathrm{SC}$ & arbóreo & zoocoria \\
\hline Solanum pseudo-quina A. St.-Hil. & inicial & arbóreo & zoocoria \\
\hline Solanum sp. 1 & $\mathrm{SC}$ & arbóreo & zoocoria \\
\hline Solanum sp. 2 & SC & arbóreo & zoocoria \\
\hline \multicolumn{4}{|l|}{ VIOLACEAE } \\
\hline Anchietea salutaris A. St.-Hil. & $\mathrm{SC}$ & liana & anemocoria \\
\hline
\end{tabular}

evidenciado para os fragmentos pequenos. A partir do arranjo dos escores das espécies e morfo-espécies no primeiro eixo, é possível distinguir um gradiente geral e grupos de espécies segregados, aparentemente associados ao fragmento "pequeno/conectado", à borda do fragmento "pequeno/isolado" e ao interior do fragmento "grande/fonte" (Fig. 2). Não foi verificada a ocorrência de disparidades que evidenciassem outliers da matriz original, tendo sido mantidas, portanto, algumas espécies que foram bem mais abundantes.

A associação mais forte apontada no primeiro eixo da DCA em relação aos atributos analisados foi com o tipo funcional das espécies, sendo que as iniciais tenderam a um extremo do eixo, associadas ao fragmento "pequeno/conectado" (ex.: Allophylus edulis, Clethra scabra, Cupania oblongifolia, Pera glabrata, Zanthoxylum rhoifolium) e as tardias tenderam ao extremo oposto, associadas ao fragmento "pequeno/isolado" (ex.: Cedrela fissilis, C. odorata, Copaifera trapezifolia, Ilex paraguayensis, Ocotea puberula, Pisonia ambigua, Posoqueria acutifolia) (Fig. 2). A análise de variância baseada nos escores confirmou essa associação das espécies iniciais com o fragmento "pequeno/conectado" e das tardias com o fragmento "pequeno/isolado", ao revelar a média dos escores das espécies iniciais significativamente menor $(\mathrm{df}=2 ; \mathrm{F}=3,544 ; \mathrm{p}=0,037)$ que a das tardias.

A correlação entre o valor ordinal representando o intervalo do primeiro eixo de escores resultantes da DCA e a respectiva incidência dos atributos (hábito, tipo funcional e síndrome de dispersão) resultou numa única relação significativa, que correspondeu ao hábito 
Tabela 4. Densidade relativa $\left(n_{i} / N\right)$ de sementes das espécies coletadas nas bordas e interiores dos fragmentos florestais estudados, bem como nos fragmentos como um todo $($ Fonte $=$ fragmento Pedroso, grande; Conect. $=$ fragmento Alcides, pequeno; Isolado $=$ fragmento Carmo Messias, pequeno).

\begin{tabular}{|c|c|c|c|c|c|c|c|c|c|c|}
\hline Espécie & $\begin{array}{c}\text { Conect. } \\
\text { borda }\end{array}$ & $\begin{array}{l}\text { Conect. } \\
\text { interior }\end{array}$ & $\begin{array}{c}\text { Conect. } \\
\text { total }\end{array}$ & $\begin{array}{c}\text { Isolado } \\
\text { borda }\end{array}$ & $\begin{array}{l}\text { Isolado } \\
\text { interior }\end{array}$ & $\begin{array}{c}\text { Isolado } \\
\text { total }\end{array}$ & $\begin{array}{l}\text { Fonte } \\
\text { borda }\end{array}$ & $\begin{array}{c}\text { Fonte } \\
\text { interior }\end{array}$ & $\begin{array}{c}\text { Fonte } \\
\text { total }\end{array}$ & Total \\
\hline Allophylus edulis & 0,00 & 0,04 & 0,02 & 0,00 & 0,00 & 0,00 & 0,00 & 0,00 & 0,00 & 0,01 \\
\hline Allophylus sp. & 0,39 & 0,00 & 0,23 & 0,00 & 0,00 & 0,00 & 0,00 & 0,00 & 0,00 & 0,14 \\
\hline Anchietea salutaris & 2,82 & 2,05 & 2,50 & 0,00 & 0,46 & 0,32 & 3,13 & 4,88 & 4,24 & 2,29 \\
\hline Bignoniaceae & 0,00 & 0,00 & 0,00 & 0,00 & 0,02 & 0,02 & 0,00 & 0,46 & 0,29 & 0,05 \\
\hline Caesalpinaceae 1 & 0,00 & 0,00 & 0,00 & 0,00 & 0,07 & 0,05 & 0,00 & 0,00 & 0,00 & 0,01 \\
\hline Calyptranthes sp. & 0,02 & 0,00 & 0,01 & 0,00 & 0,00 & 0,00 & 0,00 & 0,04 & 0,02 & 0,01 \\
\hline Capsicodendron dinisii & 0,08 & 0,22 & 0,14 & 0,00 & 0,00 & 0,00 & 0,00 & 0,04 & 0,02 & 0,09 \\
\hline Capsicodendron sp. & 0,00 & 0,01 & 0,01 & 0,00 & 0,00 & 0,00 & 0,00 & 0,00 & 0,00 & 0,00 \\
\hline Casearia sylvestris & 0,00 & 0,00 & 0,00 & 0,00 & 0,12 & 0,08 & 0,00 & 0,00 & 0,00 & 0,02 \\
\hline Cedrela fissilis & 0,00 & 0,00 & 0,00 & 0,43 & 0,05 & 0,17 & 0,13 & 0,08 & 0,10 & 0,05 \\
\hline Cedrela odorata & 0,01 & 0,00 & 0,01 & 0,05 & 0,07 & 0,07 & 0,00 & 0,00 & 0,00 & 0,02 \\
\hline Clematis sp. & 0,28 & 0,38 & 0,32 & 0,05 & 0,02 & 0,03 & 0,00 & 0,00 & 0,00 & 0,21 \\
\hline Clethra scabra & 71,99 & 79,40 & 75,09 & 0,11 & 0,14 & 0,13 & 2,00 & 7,93 & 5,77 & 48,64 \\
\hline Copaifera trapezifolia & 0,00 & 0,04 & 0,02 & 1,97 & 0,05 & 0,65 & 0,00 & 0,00 & 0,00 & 0,15 \\
\hline Cordia ecalyculata & 0,05 & 0,00 & 0,03 & 0,00 & 0,00 & 0,00 & 0,00 & 0,15 & 0,10 & 0,03 \\
\hline Cordia sp. & 0,03 & 0,00 & 0,02 & 0,00 & 0,00 & 0,00 & 0,00 & 0,38 & 0,24 & 0,05 \\
\hline Cupania oblongifolia & 0,00 & 0,13 & 0,06 & 0,05 & 0,00 & 0,02 & 0,00 & 0,00 & 0,00 & 0,04 \\
\hline Eryobothrya japonica & 0,00 & 0,07 & 0,03 & 0,00 & 0,00 & 0,00 & 0,00 & 0,11 & 0,07 & 0,03 \\
\hline Eugenia sp. & 0,00 & 0,00 & 0,00 & 0,27 & 0,00 & 0,08 & 0,27 & 0,00 & 0,10 & 0,03 \\
\hline Gochnatia polymorpha & 16,31 & 8,53 & 13,05 & 21,81 & 52,27 & 42,76 & 46,74 & 10,87 & 23,93 & 21,08 \\
\hline Gomidesia sp. & 0,00 & 0,00 & 0,00 & 0,53 & 1,59 & 1,26 & 0,00 & 0,00 & 0,00 & 0,27 \\
\hline Guatteria sp. & 0,00 & 0,00 & 0,00 & 0,00 & 0,00 & 0,00 & 0,07 & 0,00 & 0,02 & 0,00 \\
\hline Heteropterys sp. & 0,08 & 0,11 & 0,09 & 2,23 & 3,21 & 2,91 & 0,00 & 0,00 & 0,00 & 0,69 \\
\hline Ilex paraguayensis & 0,10 & 0,50 & 0,27 & 21,12 & 36,21 & 31,50 & 1,60 & 4,08 & 3,18 & 7,44 \\
\hline Lamanonia ternata & 0,00 & 0,00 & 0,00 & 0,00 & 0,00 & 0,00 & 0,00 & 25,58 & 16,27 & 2,41 \\
\hline Lauraceae 1 & 0,02 & 0,08 & 0,05 & 0,48 & 0,17 & 0,27 & 0,00 & 0,08 & 0,05 & 0,09 \\
\hline Lauraceae 2 & 0,04 & 0,04 & 0,04 & 0,00 & 0,58 & 0,40 & 0,00 & 0,08 & 0,05 & 0,12 \\
\hline Lauraceae 3 & 0,00 & 0,00 & 0,00 & 0,00 & 0,00 & 0,00 & 0,00 & 0,08 & 0,05 & 0,01 \\
\hline Leandra sp.1 & 1,58 & 0,30 & 1,04 & 0,00 & 0,00 & 0,00 & 0,33 & 0,61 & 0,51 & 0,74 \\
\hline Leandra $\mathrm{sp} .2$ & 0,20 & 0,00 & 0,12 & 0,00 & 0,00 & 0,00 & 0,00 & 0,11 & 0,07 & 0,09 \\
\hline Malpighiaceae & 0,01 & 0,00 & 0,01 & 0,00 & 0,00 & 0,00 & 0,00 & 0,00 & 0,00 & 0,00 \\
\hline Miconia sp. & 0,13 & 0,00 & 0,07 & 0,00 & 0,00 & 0,00 & 0,00 & 0,00 & 0,00 & 0,05 \\
\hline Myrcia sp. & 0,00 & 0,00 & 0,00 & 0,05 & 0,00 & 0,02 & 2,06 & 6,79 & 5,07 & 0,75 \\
\hline Myrsine ferruginea & 0,78 & 3,09 & 1,74 & 1,01 & 0,12 & 0,40 & 4,73 & 30,27 & 20,97 & 4,30 \\
\hline Myrtaceae 1 & 0,00 & 0,00 & 0,00 & 0,05 & 0,00 & 0,02 & 0,00 & 0,00 & 0,00 & 0,00 \\
\hline Myrtaceae 2 & 0,00 & 0,00 & 0,00 & 0,00 & 0,31 & 0,22 & 0,00 & 0,00 & 0,00 & 0,05 \\
\hline Myrtaceae 3 & 0,00 & 0,00 & 0,00 & 0,00 & 0,19 & 0,13 & 0,00 & 0,00 & 0,00 & 0,03 \\
\hline Ocotea puberula & 0,00 & 0,00 & 0,00 & 0,59 & 0,19 & 0,32 & 0,00 & 0,00 & 0,00 & 0,07 \\
\hline Ocotea $\mathrm{sp}$ & 0,00 & 0,03 & 0,01 & 0,00 & 0,00 & 0,00 & 0,00 & 0,00 & 0,00 & 0,01 \\
\hline Passiflora sp. & 0,03 & 0,00 & 0,02 & 0,00 & 0,00 & 0,00 & 0,00 & 0,00 & 0,00 & 0,01 \\
\hline Pera glabrata & 0,02 & 0,01 & 0,02 & 0,00 & 0,00 & 0,00 & 0,00 & 0,00 & 0,00 & 0,01 \\
\hline Piptadenia gonoacantha & 0,00 & 0,01 & 0,01 & 0,69 & 0,00 & 0,22 & 0,40 & 0,08 & 0,19 & 0,08 \\
\hline Pisonia ambigua & 0,00 & 0,00 & 0,00 & 0,00 & 0,05 & 0,03 & 0,00 & 0,00 & 0,00 & 0,01 \\
\hline Posoqueria acutifolia & 0,00 & 0,00 & 0,00 & 0,00 & 0,02 & 0,02 & 0,00 & 0,00 & 0,00 & 0,00 \\
\hline Prunus myrtifolia & 0,45 & 0,01 & 0,27 & 0,00 & 0,00 & 0,00 & 0,00 & 0,27 & 0,17 & 0,19 \\
\hline Psidium cattleyanum & 0,00 & 0,00 & 0,00 & 0,00 & 0,00 & 0,00 & 4,73 & 4,50 & 4,58 & 0,68 \\
\hline Psidium $\mathrm{sp}$ & 0,17 & 0,00 & 0,10 & 0,00 & 0,00 & 0,00 & 0,80 & 0,30 & 0,48 & 0,14 \\
\hline Psychotria sessilis & 0,96 & 0,08 & 0,59 & 0,00 & 0,36 & 0,25 & 6,46 & 0,11 & 2,42 & 0,79 \\
\hline Psychotria suterella & 0,28 & 3,46 & 1,61 & 5,37 & 2,29 & 3,26 & 8,52 & 0,99 & 3,73 & 2,28 \\
\hline Sapindaceae & 0,00 & 0,00 & 0,00 & 0,00 & 0,00 & 0,00 & 0,07 & 0,00 & 0,02 & 0,00 \\
\hline Sclerolobium denudatum & 0,00 & 0,00 & 0,00 & 0,21 & 0,10 & 0,13 & 0,00 & 0,00 & 0,00 & 0,03 \\
\hline Serjania $\mathrm{sp.}$ & 0,84 & 1,06 & 0,94 & 41,22 & 0,58 & 13,27 & 0,00 & 0,61 & 0,39 & 3,52 \\
\hline Solanum argentum & 0,00 & 0,00 & 0,00 & 0,00 & 0,00 & 0,00 & 0,33 & 0,00 & 0,12 & 0,02 \\
\hline
\end{tabular}


Tabela 4 (continuação)

\begin{tabular}{lcccccccccc}
\hline Espécie & $\begin{array}{c}\text { Conect. } \\
\text { borda }\end{array}$ & $\begin{array}{c}\text { Conect. } \\
\text { interior }\end{array}$ & $\begin{array}{c}\text { Conect. } \\
\text { total }\end{array}$ & $\begin{array}{c}\text { Isolado } \\
\text { borda }\end{array}$ & $\begin{array}{c}\text { Isolado } \\
\text { interior }\end{array}$ & $\begin{array}{c}\text { Isolado } \\
\text { total }\end{array}$ & $\begin{array}{c}\text { Fonte } \\
\text { borda }\end{array}$ & $\begin{array}{c}\text { Fonte } \\
\text { interior }\end{array}$ & $\begin{array}{c}\text { Fonte } \\
\text { total }\end{array}$ & $\begin{array}{c}\text { Total } \\
\text { Solanum pseudo-quina }\end{array}$ \\
Solanum sp. 1 & 0,16 & 0,03 & 0,11 & 1,33 & 0,43 & 0,71 & 16,84 & 0,42 & 6,40 & 1,17 \\
Solanum sp. 2 & 0,00 & 0,00 & 0,00 & 0,00 & 0,02 & 0,02 & 0,00 & 0,00 & 0,00 & 0,00 \\
Stifftia chrysantha & 0,00 & 0,00 & 0,00 & 0,00 & 0,00 & 0,00 & 0,07 & 0,00 & 0,02 & 0,00 \\
Syagrus romanzoffiana & 0,05 & 0,13 & 0,08 & 0,16 & 0,22 & 0,20 & 0,20 & 0,04 & 0,10 & 0,11 \\
Tibouchina pulchra & 0,01 & 0,00 & 0,01 & 0,00 & 0,00 & 0,00 & 0,07 & 0,00 & 0,02 & 0,01 \\
Xylopia sp. & 0,33 & 0,00 & 0,19 & 0,00 & 0,00 & 0,00 & 0,27 & 0,00 & 0,10 & 0,14 \\
Zanthoxylum rhoifolium & 0,00 & 0,00 & 0,00 & 0,00 & 0,00 & 0,00 & 0,20 & 0,00 & 0,07 & 0,01 \\
Número total de sementes (N) & 1,79 & 0,18 & 1,12 & 0,21 & 0,05 & 0,10 & 0,00 & 0,08 & 0,05 & 0,74 \\
\hline
\end{tabular}

Tabela 5. Número de sementes coletadas na borda e no interior dos fragmentos amostrados (localizados em Caucaia do Alto, SP), riqueza especifica e índice de diversidade de Shannon (H') registrados para os respectivos sítios de coleta $(* *=$ valores significativamente diferentes, $\mathrm{p}<0,01)$.

\begin{tabular}{lcc}
\hline Fragmento & Riqueza específica & $\mathrm{H}^{\prime}$ \\
\hline Grande/fonte - borda & 23 & $1,847 * *$ \\
Grande/fonte - interior & 29 & $2,038 * *$ \\
Pequeno/conectado - borda & 31 & $1,074 * *$ \\
Pequeno/conectado - interior & 26 & $0,894 * *$ \\
Pequeno/isolado - borda & 23 & $1,670 * *$ \\
Pequeno/isolado - interior & 29 & $1,230 * *$ \\
\hline
\end{tabular}

arbóreo (rho $=0,97 ; \mathrm{p}=0,005)$ (Fig. 3). Essa correlação positiva evidenciou a importância crescente do hábito arbóreo a partir do fragmento "pequeno/ conectado" - com menor incidência de arbóreas entre as sementes coletadas - em direção ao "pequeno/ isolado", no qual houve predomínio do hábito arbóreo. Outras relações observadas, cujos coeficientes de correlação (rho) alcançaram valores maiores do que 0,5 , embora não significativas, ilustram o arranjo dos atributos considerados no gradiente definido pelos fragmentos. Neste sentido, o tipo funcional "inicial" $($ rho $=-0,80)$ e o hábito "liana" (rho $=-0,67)$, correlacionados negativamente com o gradiente

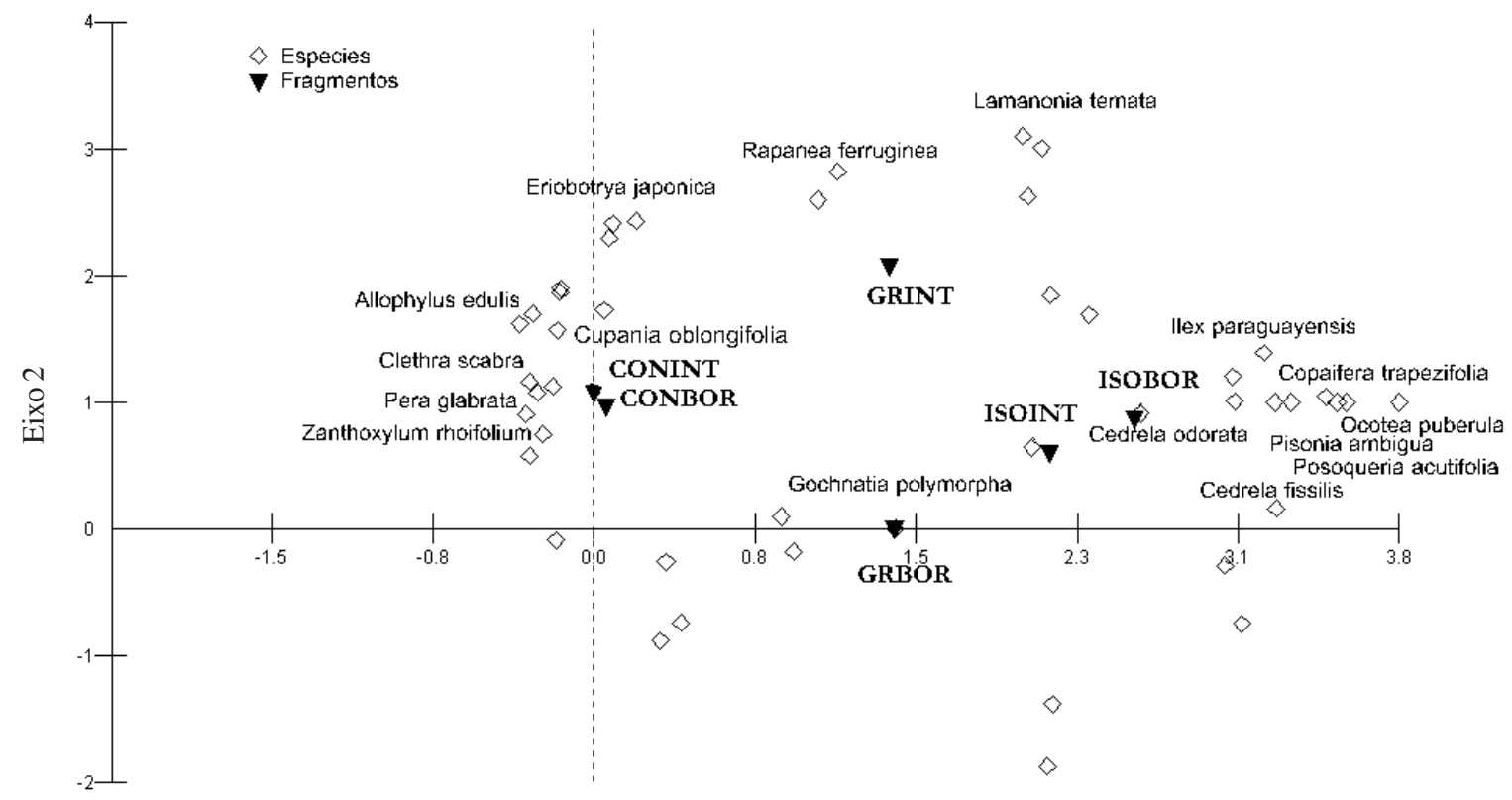

Eixo 1

Figura 2. Interpolação simultânea dos escores referentes a espécies e fragmentos no primeiro e segundo eixos resultantes da análise de correspondência (DCA) aplicada à matriz de abundância de sementes. Os eixos representados correspondem, respectivamente, a 37\% e $18 \%$ do conteúdo de informação da matriz original. São identificados os escores das espécies ressaltadas no texto (CONINT = interior do fragmento pequeno/conectado; CONBOR = borda do fragmento pequeno/conectado; ISOINT = interior do fragmento pequeno/isolado; ISOBOR = borda do fragmento pequeno/isolado; GRINT = interior do fragmento grande/fonte; GRBOR = borda do fragmento grande/fonte). 
principal, indicaram uma relação inversa com a incidência de arbóreas e, portanto, uma proporção menor no fragmento "pequeno/isolado" em relação ao "pequeno/conectado" (Fig. 3).

Os testes de independência entre a posição dos coletores nos fragmentos (borda e centro) e os atributos das espécies indicaram um conjunto de associações fortemente significativas (Tab. 6). A incidência de sementes de lianas foi positivamente associada com as bordas dos fragmentos pequenos, especialmente do "isolado" ( $p<0,01)$. O inverso foi encontrado no fragmento "grande/fonte", onde a incidência de

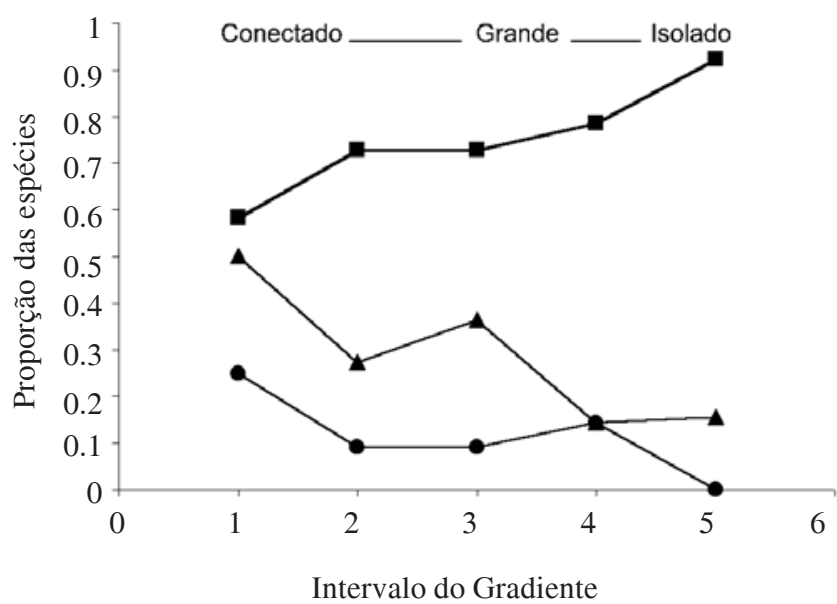

Figura 3. Proporção de espécies pertencentes aos grupos funcionais classificados em intervalos do gradiente formado pelos escores do primeiro eixo resultante da análise de correspondência. A associação do gradiente com os fragmentos é apresentada na parte superior do gráfico (Conectado = fragmento "pequeno/conectado"; Grande = fragmento "grande/fonte"; Isolado = fragmento "pequeno/isolado". - - - = arborea; $-\bullet-=$ liana; $-\mathbf{\Delta}-=$ inicial). sementes de lianas na borda foi menor do que a esperada $(\mathrm{p}<0,01)$.

A ocorrência de sementes de espécies subarbustivas e de sub-bosque foi positivamente associada com as bordas dos fragmentos "pequeno/ isolado" e "grande/fonte" $(\mathrm{p}<0,01)$. Houve ainda uma proporção menor do que a esperada de sementes de espécies arbóreas e dos estádios iniciais na borda desses fragmentos $(\mathrm{p}<0,01)$. O fragmento "pequeno/ conectado" apresentou um padrão oposto de associação entre tais atributos, ou seja, uma associação negativa entre a quantidade de sementes de espécies subarbustivas e de sub-bosque com a borda ( $\mathrm{p}<0,01)$, porém, houve uma maior proporção de sementes de espécies arbustivas do que a esperada na borda, devido a uma grande quantidade de sementes de espécies do gênero Leandra (que é arbustiva), coletadas em sua borda (Tab. 6). Também neste fragmento, a proporção de sementes de espécies de estádios iniciais foi ligeiramente superior na borda. As sementes de espécies tardias tiveram maior incidência do que a esperada na borda do fragmento "pequeno/isolado", e o contrário ocorreu para os fragmentos "pequeno/ conectado" e "grande/fonte" $(\mathrm{p}<0,01)$.

Quanto à síndrome de dispersão primária, a proporção de sementes anemocóricas na borda do fragmento "pequeno/isolado" foi alta e a de sementes de espécies zoocóricas ficou abaixo da esperada $(\mathrm{p}<0,01)$. No fragmento "grande/fonte", essas mesmas associações ocorreram, mas de forma marginalmente significativa $(\mathrm{p}<0,05)$. O fragmento "pequeno/conectado" não apresentou associações significativas entre os tipos de síndromes de dispersão das sementes e a posição de coleta (borda ou centro).

Tabela 6. Testes de independência $\left(\chi^{2}\right)$ entre a posição dos coletores no fragmento e as categorias de sementes coletadas. As combinações nas quais a independência foi rejeitada, estão representadas pela diferença entre o obtido e o esperado. Os símbolos "+” e “-" indicam respectivamente um maior ou menor número de sementes na classe representada do que o esperado ao acaso. O símbolo "=" indica um valor aproximado entre o esperado e o obtido, e o símbolo “\#” indica relações não significativas ( $\mathrm{p}>0.05$ ).

\begin{tabular}{|c|c|c|c|c|c|c|c|}
\hline & & \multicolumn{2}{|c|}{ Pequeno/isolado } & \multicolumn{2}{|c|}{ Grande/fonte } & \multicolumn{2}{|c|}{ Pequeno/conectado } \\
\hline & & Borda & Centro & Borda & Centro & Borda & Centro \\
\hline \multicolumn{2}{|c|}{ Síndrome de dispersão Anemocórica } & + & - & + & - & \# & $\#$ \\
\hline & Zoocórica & - & + & - & + & \# & \# \\
\hline & Barocórica & + & - & + & - & \# & $\#$ \\
\hline \multirow[t]{3}{*}{ Hábito } & Liana & + & - & - & + & + & - \\
\hline & Sub-arbusto & + & - & + & - & - & + \\
\hline & Árvore & - & + & - & + & $=$ & $=$ \\
\hline \multirow[t]{3}{*}{ Grupo funcional } & Inicial & - & + & - & + & + & - \\
\hline & Tardia & + & - & - & + & - & + \\
\hline & Sub-bosque & + & - & + & - & - & + \\
\hline
\end{tabular}




\section{Discussão}

A maior parte das famílias melhor representadas entre as sementes coletadas neste estudo é também freqüentemente encontrada em outros remanescentes florestais do Estado de São Paulo (Leitão Filho 1992; Rossi 1994; Tabarelli et al. 1999; Pivello \& Peccinini 2002). L. Alves \& J.P. Metzger (dados não publicados), num estudo com plântulas e indivíduos jovens de espécies arbóreas em 15 fragmentos florestais na mesma região deste estudo, encontraram as mesmas cinco famílias mais frequentes. A grande maioria das espécies aqui coletadas $(73,7 \%)$ caracterizou-se como zoocórica e muito poucas foram as sementes de espécies autocóricas $(3,5 \%)$, o que também foi verificado por L. Alves \& J.P. Metzger (dados não publicados). Outros autores (Howe \& Smallwood 1982; Morellato \& Leitão Filho 1992) já haviam ressaltado que 50 a $90 \%$ das espécies arbustivoarbóreas de florestas tropicais têm dispersão primária por zoocoria e poucas são autocóricas.

Considerando-se que florestas tropicais mais maduras tendem a ter um alto índice de espécies zoocóricas, dispersas por vertebrados (Morellato \& Leitão Filho 1992; Tabarelli et al. 1999; Webb \& Peart 2001), e, portanto, sementes maiores e em menor número na chuva de sementes, o número e a densidade de sementes aqui coletadas apontam para um maior amadurecimento da comunidade no fragmento "pequeno/isolado", seguido do "grande/fonte" e, por fim, do "pequeno/conectado". Neste último, quase $90 \%$ das sementes coletadas foram de espécies anemocóricas, enquanto que nos outros dois fragmentos, a chuva de sementes contou com espécies zoocóricas dentre as mais abundantes.

Foi evidenciada, por meio da DCA, a existência de uma clara situação de borda $v s$. interior para o fragmento "grande/fonte", muito provavelmente em decorrência do tamanho desse fragmento. Também a maior diversidade encontrada para o fragmento "grande/fonte", especialmente em seu interior, aponta para uma situação de maior equilíbrio na comunidade. Os fragmentos pequenos, ao contrário, apresentaram, de acordo com a DCA, situações semelhantes entre borda e interior, pois seu pequeno tamanho os torna mais homogêneos, praticamente sem área de interior, como também observado por outros autores em fragmentos menores que 10 ha (Benitez-Malvido 1998; Tabarelli et al. 1999; Oosterhoorn \& Kappelle 2000). No entanto, ao se analisar mais detalhadamente os três parâmetros considerados para as espécies (hábito, síndrome de dispersão e tipo funcional), verifica-se que os fragmentos "pequeno/isolado" e "grande/fonte" se assemelham em relação aos tipos de sementes coletadas nas posições de borda e interior. Em ambos, há uma maior abundância de sementes de espécies dos estádios iniciais e anemocóricas nas bordas, e de espécies tardias e zoocóricas no centro, confirmada pelo teste de independência. Esses padrões, assim como a maior abundância de lianas na borda do fragmento "pequeno/isolado", condizem com o esperado pelos efeitos de borda (Aizen \& Feinsinger 1994; Murcia 1995; Fox et al. 1997; Oosterhoorn \& Kappelle 2000; Schnitzer \& Bongers 2002; Fahrig 2003) e sugerem uma situação de borda $v s$. interior também para o fragmento "pequeno/isolado". O fragmento "pequeno/ conectado", por sua vez, não apresentou relação entre a posição dos coletores e a síndrome de dispersão. Houve ainda uma associação positiva significativa para a ocorrência de sementes de espécies subarbustivas e de sub-bosque nas bordas dos fragmentos "pequeno/ isolado" e "grande/fonte", tendo o contrário ocorrido para o fragmento "pequeno/conectado". Assim, embora essa análise mais detalhada permita diferenciar uma área de borda não apenas no fragmento "grande/ fonte" como também no "pequeno/isolado", essas bordas são relativamente densas a ponto de suportar indivíduos que exigem sombreamento, fato este confirmado em observações de campo. Essa análise detalhada continua apontando para uma homogeneidade estrutural e a não existência de uma borda definida no fragmento "pequeno/conectado".

A análise acima mostra que há alguma influência do tamanho do fragmento sobre o padrão das sementes contidas na chuva de sementes, embora não totalmente linear. Os outros dois fatores potencialmente influentes nos padrões das chuvas de sementes aqui verificados - a estrutura da vegetação e o grau de conectividade estrutural do fragmento na paisagem - também contribuíram para determinar padrões nas chuvas de sementes. Dentre estes, os fatores internos notadamente a estrutura da vegetação, avaliada por parâmetros diretamente mensurados (como densidade de árvores de maior porte, quantidade de bromélias, abertura do dossel) e pelo índice de perturbação, e indiretamente, por meio dos parâmetros considerados na análise de correspondência (DCA) - foram mais determinantes na composição da chuva de sementes do que fatores externos, como o grau de conectividade a outros fragmentos florestais. Na DCA, a característica que mostrou maior correlação com o principal eixo de escores foi o "hábito", podendo indicar 
um gradiente estrutural como causa do arranjo entre as unidades. A correlação significativa entre "hábito" e os escores das espécies no primeiro eixo sugerem o predomínio de características distintas de porte e forma de vida entre os fragmentos pequenos "isolado" e "conectado". O fragmento "pequeno/isolado", contrariamente ao esperado, é o que possui a estrutura de mata mais desenvolvida, com árvores de grande porte, dossel mais fechado, maior quantidade de epífitas, e menor de lianas - padrões geralmente associados à boa estrutura da floresta - e poucos sinais de perturbação (Tab. 2; Fig. 3); mostrou-se associado a espécies tardias e a totalidade de sua área encontra-se em estádio sucessional médio/avançado (Fig. 3; Tab. 1). Apesar de seu isolamento, sua estrutura florestal ainda está mais bem preservada do que a do fragmento "pequeno/conectado", apesar deste possuir maior conectividade florestal.

Justamente pelo fato do fragmento "pequeno/ isolado" ter apresentado a vegetação com melhor estrutura, algumas das relações esperadas entre o grau de conectividade na paisagem e as características da chuva de sementes não foram confirmadas, como o aumento de espécies tardias e zoocóricas com a maior conectividade do fragmento. Essa relação direta não se confirmou para os fragmentos pequenos. Entretanto, embora tenha sido apontada a associação do fragmento "pequeno/isolado" com espécies mais tardias, as espécies dominantes (em número de sementes) em todos os fragmentos - inclusive no "pequeno/isolado" - são árvores características dos estádios sucessionais iniciais: Clethra scabra, Gochnatia polymorpha, Myrsine ferruginea e Lamanonia ternata. Essa dominância de espécies iniciais está provavelmente associada ao fato de praticamente todos os fragmentos florestais da região já terem sofrido corte seletivo, sendo, portanto, secundários e provenientes da regeneração de florestas alteradas. Os três fragmentos aqui analisados mostraram sinais de perturbação antropogênica, refletidos em seus respectivos índices de perturbação. Dentre eles, corte seletivo e corte do sub-bosque foram as alterações mais frequentes.

Este estudo mostrou uma nítida oposição entre os efeitos de conectividade e de estrutura da vegetação nos fragmentos analisados. A estrutura da vegetação foi mais importante na determinação dos padrões encontrados quanto ao hábito, tipo funcional e síndrome de dispersão das espécies contidas nas chuvas de sementes do que a conectividade da paisagem. Os padrões encontrados evidenciaram uma boa qualidade ecológica (dada pelo estádio sucessional, grau de perturbação e estrutura da vegetação) do fragmento "pequeno/isolado", apesar de sua situação de isolamento na paisagem.

Esse resultado ressalta a importância de se dedicar maior atenção à conservação de pequenos fragmentos, mesmo que isolados na paisagem, especialmente aos que ainda mantêm uma boa estrutura da vegetação, não somente preservando-os, como também implementando ações de manejo, a fim de evitar que efeitos de borda os levam à degradação. Tais pequenos fragmentos podem servir como importantes fontes de sementes para a recomposição de áreas degradadas no entorno.

Embora o pequeno número de fragmentos analisados neste estudo e a falta de réplicas para cada situação de tamanho e conectividade estrutural dos fragmentos não permitiram verificar padrões gerais, este é, até o momento, o primeiro estudo em florestas brasileiras que busca relacionar chuva e dispersão de sementes às características estruturais da paisagem. Novos estudos nesse sentido são necessários, uma vez que o entendimento de como a fragmentação dos habitats afeta padrões ecológicos tornou-se fundamental para a conservação e recuperação dos remanescentes de ambientes nativos.

\section{Agradecimentos}

Os autores são gratos à FAPESP, pelo auxílio financeiro concedido ao projeto "Conservação da Biodiversidade em Paisagens Fragmentadas no Planalto Atlântico de São Paulo" (processo 99/05123-4, Projeto Biota - FAPESP), do qual este trabalho foi parte, e pela bolsa de estudos concedida a duas das autoras (processo 00/14605-1). Também agradecem o auxílio em campo prestado pelos técnicos Paulo César Fernandes e Maurício Perine.

\section{Referências bibliográficas}

Aizen, M.A. \& Feinsinger, P. 1994. Forest fragmentation, pollination, and plant reproduction in a chaco dry forest, Argentina. Ecology 75: 330-351.

Barroso, G.M.; Morim, M.P.; Peixoto, A.L. \& Ichaso, C.L.F. 1999. Frutos e Sementes - Morfologia Aplicada à Sistemática de Dicotiledôneas. Viçosa, Ed. da Universidade Federal de Viçosa.

Beier, P. \& Noss, R.F. 1998. Do habitat corridors provide connectivity? Conservation Biology 12(6): 1241-1252.

Benitez-Malvido, J. 1998. Impact of forest fragmentation on seedling abundance in a tropical rain forest. Conservation Biology 12(2): 380-389. 
Clark, J.S.; Silman, M.; Kern, R.; Macklin, E. \& HilleRisLambers, J. 1999. Seed dispersal near and far: patterns across temperate and tropical forests. Ecology 80: $1475-1494$.

Collinge, S.K. 1998. Spatial arrangement of habitat patches and corridors: clues from ecological field experiments. Landscape and Urban Planning 42: 157-168.

Dean, W. 1996. A ferro e fogo - a história e a devastação da Mata Atlântica Brasileira. São Paulo, Companhia das Letras.

Fahrig, L. 2003. Effects of habitat fragmentation on biodiversity. Annu. Rev. Ecol. Evol. Syst., 34: 487-515.

Fenner, M. 1985. Seed Ecology. New York, Chapman \& Hall.

Fox, B.J.; Taylor, J.E.; Fox, M.D. \& Williams, C. 1997. Vegetation changes across edges of rainforest remnants. Biological Conservation 82: 1-13.

Gandolfi, S. 1991. Estudo florístico e fitossociológico de uma floresta residual na área do Aeroporto Internacional de São Paulo, município de Guarulhos, SP. Dissertação de Mestrado. Instituto de Biologia, Universidade Estadual de Campinas, Campinas, SP.

Godefroid, S. \& Koedam, N. 2003. How important are large vs. small forest remnants for the conservation of the woodland flora in an urban context? Global Ecology \& Biogeography 12: 287-298.

Gorchov, D.L.; Cornejo, F.; Ascorra, C. \& Jaramillo, M. 1993. The role of seed dispersal in the natural regeneration of rain forest after strip-cutting in the Peruvian Amazon. Vegetatio 107/108: 339-349.

Guevara, S. \& Laborde, J. 1993. Monitoring seed dispersal at isolated standing trees in tropical pastures: consequences for local species availability. Vegetatio 107/108: 319-338.

Hardesty, B.D. \& Parker, V.T. 2002. Community seed rain patterns and a comparison to adult community structure in a West African tropical forest. Plant Ecology 164: 49-64.

Harper, J.L. 1977. Population Biology of Plants. London, Academic Press.

Howe, H.F. \& Smallwood, J. 1982. Ecology of seed dispersal. Annual Review of Ecology and Systematics 13: 201-228.

Instituto Agronômico de Campinas - CIIAGRO (Centro Integrado de Informação Meteorológica) s/data. CIIAGRO on line. Governo do Estado de São Paulo, São Paulo. Disponível em: http://www.iac.sp.gov.br. (Acesso: 26/04/2003).

Instituto Florestal de São Paulo 2004. Reserva da Biosfera do Cinturão Verde da Cidade de São Paulo. Disponível em: http://www.iflorestsp.br (Acesso: 12/01/2005).

Jongman. R.H.G.; Ter Braak, C.J.F. \& Van Tongeren, O.F.R. 1996. Data Analysis in Community and Landscape Ecology. Cambridge, U.K., Cambridge University Press.

Köeppen, W. 1948. Climatologia: con un estudio de los climas de la tierra. México, Fundo de Cultura Econômica.

Laurance, S.G. \& Laurance, W.F. 1999. Tropical wildlife corridors: use of linear rainforest remnants by arboreal mammals. Biological Conservation 91: 231-239.
Leitão Filho, H.F. 1992. A flora arbórea da Serra do Japi. Pp. 4063. In: L.P.C. Morellato (org.). História Natural da Serra do Japi: Ecologia e Preservação de uma Área Florestal no Sudeste do Brasil. Campinas, Editora da Unicamp.

Lorenzi, H. 1992. Árvores Brasileiras. v. I, II. Nova Odessa, Plantarum Ed.

Magurran, A.E. 1988. Ecological Diversity and its Measurement. Cambrigde, U.K., Cambridge University Press.

Martínez-Ramos, M. \& Souto-Castro, A. 1993. Seed rain and advanced regeneration in a tropical rain forest. Vegetatio 107/108: 299-318.

McGarigal, K. \& Marks, B.J. 1995. FRAGSTATS: Special Pattern Analysis Program for Quantifying Landscape Structure. Department of Agriculture, Forest Service, Pacific Northwest Research Station (Gen. Tech. Rep. PNW-GTR, 351), Portland, U.S.

Metzger, J.P. \& Décamps, H. 1997. The structural connectivity threshold: a hypothesis in conservation biology at the landscape scale. Acta Ecologica 18: 1-12.

Metzger, J.P. 2000. Tree functional group richness and landscape structure in a Brazilian tropical fragmented landscape. Ecological Applications 10(4): 1147-1161.

Metzger, J.P.; Simonetti, C.; Uezu, A.; Diederichsen, A. \& Goulart, W. 2003. Estrutura da paisagem em Caucaia do Alto (Planalto de Ibiúna, SP). Anexo I. In: J.P. Metzger (ed.). Conservação da Biodiversidade em Paisagens Fragmentadas no Planalto Atlântico de São Paulo. Relatório técnico no 99/05123-4. São Paulo, Fapesp.

Morellato, L.P.C. \& Leitão Filho, H.F. 1992. Padrões de frutificação e dispersão na Serra do Japi. Pp. 112-141. In: L.P.C. Morellato (org.). História Natural da Serra do Japi: Ecologia e Preservação de uma Área Florestal no Sudeste do Brasil. Campinas, Editora da Unicamp.

Mueller-Dombois, D. \& Ellenberg, H. 1974. Aims and Methods of Vegetation Ecology. New York, John Wiley.

Murcia, C. 1995. Edge effects in fragmented forests: implications for conservation. Trends in Ecology \& Evolution 10(2): 58-62.

Oosterhoorn, M. \& Kappelle, M. 2000. Vegetation structure and composition along an interior-edge-exterior gradient in a Costa Rican montane cloud forest. Forest Ecology and Management 126: 291-307.

Pivello, V.R. \& Peccinini. A.A. 2002. A Vegetação do PEFI. Pp. 76-93. In: D.C. Bicudo; M.C. Forti \& C.E.M. Bicudo (orgs.). Parque Estadual das Fontes do Ipiranga (PEFI): Unidade de Conservação que Resiste à Urbanização de São Paulo. São Paulo, Secretaria do Meio Ambiente do Estado de São Paulo.

Ross, J.L.S. \& Moroz, I.C. 1997. Mapa Geomorfológico do Estado de São Paulo (escala 1:500.000). v. I. São Paulo, USP-FFLCH/IPT/Fapesp, SP.

Rossi, L. 1994. A flora arbóreo-arbustiva da mata da Reserva da Cidade Universitária "Armando Salles de Oliveira" (São Paulo, Brasil). Boletim do Instituto de Botânica 9: 1-105.

Schnitzer, S.A. \& Bongers, F. 2002. The ecology of lianas and their role in forests. Trends in Ecology \& Evolution 17(5): 223-230. 
Serra, J. 1982. Image analysis and mathematic morphology. New York, Academic Press.

Tabarelli, M.; Mantovani, W. \& Peres, C.A. 1999. Effects of habitat fragmentation on plant guild structure in the montane Atlantic forest of southeastern Brazil. Biological Conservation 91: 119-127.

Taylor, P.D.; Fahrig, L.; Henein, K. \& Merriam, G. 1993. Connectivity is a vital element of landscape structure. Oikos 68: 571-573.

Terborgh, J. 1990. Seed and fruit dispersal-commentary. Pp. 181-190. In: K.S. Bawa \& M. Handley (eds.). Reproductive Ecology of Tropical Forest Plants. Paris, The Parthenon Group.

Tilman, D. 1999. Ecology- Diversity by default. Science 283: 495-496.

Uezu, A.; Metzger, J.P. \& Vielliard, J.M.E. 2005. Effects of structural and functional connectivity and patch size on the abundance of seven atlantic forest bird species. Biological Conservation 123: 507-519.
Van der Pijl, L. 1982. Principles of Dispersal in Higher Plants. Berlin, Springer-Verlag.

Veloso, H.P.; Rangel Filho, A.L.R. \& Lima, J.C.A. 1991. Classificação da Vegetação Brasileira Adaptada a um Sistema Universal. Rio de Janeiro, IBGE.

Venable, D.L. \& Brown, J.S. 1993. The populationdynamic functions of seed dispersal. Vegetatio 107/108: 31-55.

Webb, C.O. \& Peart, D.R. 2001. High seed dispersal rates in faunally intact tropical rain forest: theoretical and conservation implications. Ecology Letters 4: 491-499.

Wheelwright, N. 1993. Fruit size in a tropical tree species: variation, preference by birds and heritability. Vegetatio 107/108: 163-174.

Wilson, M.F. 1993. Dispersal mode, seed shadows and colonization patterns. Vegetatio 107/108: 261-280.

Zar, J.H. 1999. Biostatistical Analysis. $4^{\text {th }}$ ed. Upper Saddle River, Prentice Hall. 